\title{
Perceived Program Components of Omotenashi Family Experiences Learning Program in Japan: Qualitative Study of Families of Persons with Mental Disorders
}

\author{
Masako Kageyama1*, Keiko Yokoyama², Yukako Nakamura3 ${ }^{3}$ Iwao Oshima4 \\ ${ }^{1}$ Area of Integrated Health and Nursing Science, Osaka University Graduate School of Medicine, Suita, Japan \\ ${ }^{2}$ Department of Nursing, Faculty of Health Sciences, Saitama Prefectural University, Koshigaya, Japan \\ ${ }^{3}$ Department of Psychiatry, Nagoya University Graduate School of Medicine, Nagoya, Japan \\ ${ }^{4}$ Japan College of Social Work, Kiyose, Japan \\ Email: *kageyama@sahs.med.osaka-u.ac.jp
}

How to cite this paper: Kageyama, M., Yokoyama, K., Nakamura, Y. and Oshima, I. (2017) Perceived Program Components of Omotenashi Family Experiences Learning Program in Japan: Qualitative Study of Families of Persons with Mental Disorders. Open Journal of Nursing, 7, 671-682. https://doi.org/10.4236/ojn.2017.76050

Received: May 15, 2017

Accepted: June 20, 2017

Published: June 23, 2017

Copyright (๑) 2017 by authors and Scientific Research Publishing Inc. This work is licensed under the Creative Commons Attribution International License (CC BY 4.0).

http://creativecommons.org/licenses/by/4.0/ (c) (i) Open Access

\begin{abstract}
Families need sufficient learning opportunities about mental illness. Therefore, family peer education program has been developed in Japan following the U.S. and Hong Kong. We aimed to identify program components that families recognize which would provide suggestions in modifying the program. We used qualitative and inductive study design. Data were collected through group interviews for six family research participants. We coded the data to focus on relationships between program components, program processes, and impacts. Data Analysis resulted in seven assumptions based on causal relationships and three types of program components: program form, learning style and facilitation skills. The program form is family-led peer group, closed-membership, 5 times per course, and small group. The learning style is combination of textbook and experiential knowledge, family peer learning, and sharing experiences. The facilitation skills are group work focusing on strengths of family members, the acceptance of emotional disclosure, omotenashi, and teamwork skills.
\end{abstract}

\section{Keywords}

Mental Disorders, Schizophrenia, Family Support, Family Education,

Program Evaluation, Program Component

\section{Introduction}

Among developed countries, Japan is widely known to have a high psychiatric 
bed ratio. Mental health policy in Japan has shifted its emphasis from hospitalization to community-based services. However, $85 \%$ of families live with persons with severe mental illness and provide day-to-day care themselves [1]. The education is the most-needed form of support for their families [2] and is often provided by nurses in psychiatric hospitals and community setting; over $20 \%$ of families surveyed reported that it took more than three years for them to gain sufficient information about the mental illness of their loved ones in Japan [3]. To promote a national policy of deinstitutionalization, families should have sufficient opportunities to learn about mental illness.

In the US, the National Alliance on Mental Illness (NAMI) developed family peer education programs-the Family-to-Family Education Program (FFEP) in 1991 [4] and Journey of Hope (JOH) in 1993 [5]. These programs have provided by local family groups and have spread throughout the country. Another program, Family Link Education Program has developed in Hong Kong in 2000 [6]. These family peer education program models are one of family education models and are different from family psychoeducation models. Family education models are independent of treatment and focus on improving family own outcomes [7]. A project team of family members and professionals discussed possible solutions and possibilities of the adaptation of existed foreign programs. After the discussion, they developed their own original family peer education program Omotenashi Family Experiences Learning Program (Omotenashi-FELP) in 2007. This program takes into account cultural and social differences faced by families in Japan, as opposed to by families from other countries. By the end of March 2015, this program had spread, serving over 1500 families in Japan.

Ninomiya conducted pre- and post-evaluations of the program, and demonstrated the effectiveness of the program in the reduction of anxiety and the empowerment of both family attendees and facilitators [8]. The Omotenashi-FELP was developed based not on social-science theories but on the ideas, experiences, and thoughts of family members. We considered that identifying program components from the perspectives of families would provide additional suggestions in terms of modifying to more effective and efficient program. Thus, this study aims to identify program components of the program that families recognize.

\section{Methods}

\subsection{Study Design}

We used qualitative and inductive study design. This is a secondary analysis for a qualitative study to describe the process that Omotenashi-FELP has impact on family attendees, family facilitators, family groups and other surrounds.

\subsection{General Description of the Program}

The Omotenashi-FELP is a systematic learning program with a peer learning style and small group size. Each course is held on 5 sessions (approximately 3 hours per session). Courses use an 85 -page simple mental health psychoeducational textbook, and the material is communicated by a team of family facilita- 
tors. Textbook includes knowledge regarding symptoms and treatment of schizophrenia, rehabilitation for serious mental illnesses, and family coping. All facilitation teams consist of three-six family facilitators who have undergone a one-day training course.

\subsection{Research Participants}

The research participants were all family members from the project team composed of seven family members and five professionals. They played core roles in developing and disseminating the program for four to five years until 2012. Only one declined, citing illness. Four research participants were women, and two were men. Two of them are in their 50s, 60s, and 70s, respectively. All of them had children who were diagnosed with schizophrenia (duration: $\geq 10$ years). They had served as family facilitators in two-four courses, family advisers (who train and advise family facilitators) $>10$ times, and lecturers in training sessions or lessons 6 - 31 times each.

\subsection{Data Collection}

Data were collected through semi-structured group interviews lasting approximately 2 hours. Interviews were conducted once at the associations to which each of the six research participants belonged; a total of three group interviews were conducted. The first and second authors who were qualified nurses on the project's team conducted the interviews. The interviews began with the following questions that were answered by each individual: "What were your experiences from the time of your family member's onset of illness?" Next, all of the interviewees were asked the following question to obtain information about the program's implementation: “How was the program conducted?" We also asked each interviewee, "What changes did you notice in yourself or your ill family member and your family's group activities during and after your time as a facilitator?" Interviews were recorded and transcribed with the research participants' permission. In addition to the interview transcripts, we included the following program-related materials in our analysis: program manuals, training materials, articles published in family association newsletters, and published essays.

\subsection{Analysis}

Weiss [9] suggested that the program evaluation shows the assumptions underlying the program and theories that support the assumptions. To identify causal relationships between program components, program processes and impacts that developed to the assumptions, we first extracted research participants' descriptions regarding program components and the changes caused by them, from all interview transcripts and supplementary materials. Next, according to the causal-consequence model that is one of coding way [10], we coded the data to focus on program components of causal relationships between program components, program processes, and impacts in order to clarify important program components and their impacts rather than to find leading program com- 
ponents of targeted impacts. To make valid assumptions of the perceived program theory, we confirmed if the causal relationships can be supported by social-science theories, and research participant-based evidence.

After we created tentative assumptions, research participants were asked to discuss them in a meeting, in which we explained the assumptions, our interpretations of the data, and supportive theories or evidence. We encouraged research participants to discuss and correct the assumptions until all agreed with them. This study was conducted under the supervision of a richly-experienced researcher in qualitative studies.

\subsection{Ethical Considerations}

The study was approved by Saitama Prefectural University, with which one of the coauthors is affiliated. Research participants were informed of the purpose and methods of the study, that participation was voluntary, and that they could refuse to participate or withdraw from the study at any time. They were also assured of their anonymity, and their written consent was obtained.

\section{Results}

Analysis of the interview transcripts and supplemental materials resulted in seven assumptions. We discussed the perceived validity of their findings with research participants. After minor modifications, they agreed to the seven assumptions, which are discussed in detail below. The program components, program processes and impacts identified from the seven assumptions are shown in Table 1. The words with quotation mark are extracted from families' descriptions.

\subsection{Small, Closed Groups Facilitated by Family Members Highlight the Universality of Family and Create High Cohesion; This Leads to a Positive Group Dynamic}

The Omotenashi-FELP program has the basic structure of a family-led peer group. These groups have closed membership and meet five times each. Research participants appreciate this structure that has "enough time to learn and communicate" which leads to develop rapport with one another. This structure supports recognition of human universality, addressing feelings of being different and alone. The cultivation of feelings of universality helps family attendees to realize that "it was not only me" same as we are all in the same boat by Yalom \& Leszcz [11]. This universality is a therapeutic factor of the group format and a powerful source of relief in the early stages of group development [11].

Family facilitators and attendees engage in "open and honest dialogue" characterized by equal interaction without distinctions of status. The efficacy of such a structure is supported by theories on group dynamics and the functioning of self-help groups. Horizontal rather than vertical interaction among members is a structural characteristic that predicts good functionality in self-help groups [12]. This type of interaction is related to cohesiveness and is a key basis for positive group dynamics [11]. The importance of this point is highlighted by quotes 
Table 1. Seven assumptions and program components.

\begin{tabular}{|c|c|c|c|}
\hline $\begin{array}{l}\text { Types of program components } \\
\text { Contents of program components }\end{array}$ & Assumptions & Program processes & Impacts \\
\hline $\begin{array}{l}\text { Program form } \\
\text { Family-led peer group } \\
\text { Closed-membership } \\
\text { Five times per course } \\
\text { Small group }\end{array}$ & $\begin{array}{l}\text { 1) Small, closed groups facilitated by family members highlight the } \\
\text { universality of family and create high cohesion; this leads to a positive } \\
\text { group dynamic. }\end{array}$ & $\begin{array}{l}\text { Universality } \\
\text { High cohesion } \\
\text { Positive group } \\
\text { dynamics }\end{array}$ & \\
\hline \multicolumn{4}{|l|}{ Learning style } \\
\hline $\begin{array}{l}\text { Combination of textbook and } \\
\text { experiential knowledge }\end{array}$ & $\begin{array}{l}\text { 2) A textbook-based learning style in which experiential knowledge is } \\
\text { shared leads to increased knowledge, insight, and self-awareness. }\end{array}$ & $\begin{array}{l}\text { Insight } \\
\text { Self-awareness }\end{array}$ & $\begin{array}{l}\text { Embeddedness of } \\
\text { knowledge }\end{array}$ \\
\hline Family peer learning & $\begin{array}{l}\text { 3) A family-led peer learning style decreases loneliness and promotes } \\
\text { both self-acceptance of disability and embeddedness of knowledge. }\end{array}$ & & $\begin{array}{l}\text { Reduced isolation } \\
\text { Disability } \\
\text { acceptance } \\
\text { Embeddedness of } \\
\text { knowledge }\end{array}$ \\
\hline \multirow[t]{2}{*}{ Sharing experiences } & $\begin{array}{l}\text { 4) Understanding persons with mental illness and learning how to } \\
\text { handle difficulties through sharing experiential knowledge improves } \\
\text { family relationships. }\end{array}$ & & \multirow[t]{2}{*}{$\begin{array}{l}\text { Better family } \\
\text { relationships }\end{array}$} \\
\hline & $\begin{array}{l}\text { 5) Some families find hope by sharing their experiences with other } \\
\text { families and serving as models for other families. They look back on how } \\
\text { far they have come to understand the extent of their own recovery. }\end{array}$ & $\begin{array}{l}\text { Self-awareness } \\
\text { Hope }\end{array}$ & \\
\hline \multicolumn{4}{|l|}{ Facilitation skills } \\
\hline $\begin{array}{l}\text { Group work focusing on families' } \\
\text { strengths } \\
\text { Acceptance of emotional disclosure }\end{array}$ & $\begin{array}{l}\text { 6) Group work focusing on families' strengths and the acceptance of } \\
\text { emotional disclosure is linked to reduced self-stigma. }\end{array}$ & Catharsis & \multirow[t]{2}{*}{$\begin{array}{l}\text { Reduced } \\
\text { self-stigma }\end{array}$} \\
\hline $\begin{array}{l}\text { Omotenashi } \\
\text { Group facilitation with teamwork } \\
\text { skills }\end{array}$ & $\begin{array}{l}\text { 7) Group facilitation with Omotenashi and teamwork skills in family } \\
\text { facilitators accelerate interaction among group members. }\end{array}$ & $\begin{array}{l}\text { Higher interaction } \\
\text { Positive group } \\
\text { dynamics }\end{array}$ & \\
\hline
\end{tabular}

from a family attendee which were printed in a family association newsletter and a research participant' interview:

"When I found out that other families live with the same thoughts and prayers under the same sky, it was heartening to realize that I am not alone".

"It is important for family facilitators and attendees to be equal, not hierarchical, so that everyone feels safe talking about themselves".

\subsection{A Textbook-Based Learning Style in Which Experiential Knowledge Is Shared Leads to Increased Knowledge, Insight, and Self-Awareness}

In the Omotenashi-FELP, family facilitators and attendees share their own experiences after reading sections of the psychoeducational textbook. They affirm that the process "organizes all of the pieces of my experience into one whole experience", with the textbook serving as "a catalyst to talk about experiences". A simple textbook is more effective than a complex one, as it prompts families to recall their own experiences associated with the information. Speaking about their experiences in conjunction with the textbook leads families to "place and interpret the knowledge personally" or understand the knowledge in light of their own experiences. This is supported by local understanding in narrative 
therapy. In this context, local refers to the language, meaning, and understanding developed during dialogue rather than broadly held cultural sensibilities. One interprets memories, perceptions, and histories through local understanding [13].

Research participants also said, “...speaking about myself makes me organize my own story and helps me to see myself from a third-person perspective", which leads to gains in insight and self-awareness. This is supported by the creation of a narrative through self-reflection and its communication to others [14]. Gergen \& Gergen [15] define self-narrative as an individual's account of the relationships between life-relevant events across time; they believe that this process imparts life with meaning and direction. As one research participant stated:

"Through the process of combining knowledge with experiences, I came to understand that this symptom was also present in my family; I realized that what I had been worried about was this illness-related problem. This way of organizing my experiences has been helpful to me".

\subsection{A Family-Led Peer Learning Style Decreases Loneliness and Promotes both Self-Acceptance of Disability and Embeddedness of Knowledge}

A sense of isolation is fostered when a person does not accept his/her family member's mental illness. A family member of a person with mental illness might investigate what is happening with the person who is ill through independent study. However, when answers cannot be found, isolation ensues; this is the stage of discovery and denial in family recovery [16]. Through family-led peer learning, families can gradually accept the presence of mental illness; such acceptance forms the basis of all other learning. Once families have accepted this knowledge, it is considered to be embedded. FFEP attendees also gain knowledge, information, and support together [17]. Although no theory directly supports synergy between knowledge embeddedness and acceptance of disability, the research participants believed that "families cannot absorb knowledge without acceptance of disability". Several research participants emphasized that important point in interviews and an article:

"I was afraid that I would read a book and think, 'My son might change as described in this book'. I knew it was necessary to learn, but I associated knowledge on this topic with what was happening with my son, and it was difficult to accept my son's illness. Learning by myself fueled feelings of isolation".

"Families listen to other families who say they feel the same way and realize that they do not have to deny their feelings. It is hard to accept a family member's mental illness. However, though feelings of acceptance may waver, one can proceed steadily in the program".

\subsection{Understanding Persons with Mental Illness and Learning How to Handle Difficulties through Sharing Experiential Knowledge Improves Family Relationships}

Experiential knowledge that is truth learned from personal experience with a phenomenon [18]. Through sharing knowledge on textbook and experience 
knowledge in this program, families come to understand mental illness and learn to communicate with those who have it. As one family attendee said in the last class, "Now I am the person who understands my son best". Through the program, families have improved their communication and relationships with mentally ill family members. This assumption is supported by problem-focused theory on stress coping [19]. Through the program, families share their experiential knowledge in order to learn valuable coping skills, which in turn strengthen family relationships. One research participant stated:

"My relationship with my son changed dramatically through this program. I used to ask my son often about his job prospects, but I learned in this program that it is better not to ask about that. After I tried not to ask him, he began to tell me spontaneously about things with which he was struggling. In recent years, he has given me flowers on my birthday".

\subsection{Some Families Find Hope by Sharing Their Experiences with Other Families and Serving as Models for Other Families. They Look Back on How Far They Have Come to Understand the Extent of Their Own Recovery}

In the program, families in different stages of caring for persons with mental illness share their experiences with each other. Some families who were still in the early stages became inspired by contact with those who had trod the same path, raising their expectations regarding their own possibilities. Yalom [11] refers to this instillation of hope as one of the therapeutic factors of group psychotherapy. When families at later stages watch others follow their example, they see their progress and become aware of the extent of their own recovery. A family attendee and a research participant stated how they were inspired by other families:

"The most impressive thing was the self-introduction by the family facilitators. All of the facilitators enjoy different hobbies and interests, and they all seem to live cheerful, vigorous, hopeful lives. When I saw the facilitators speaking about themselves so vigorously, I became hopeful that I would be able to enjoy my life as well".

"The stories told by families in the early stages reminded me of how I felt in the beginning - it was tough even to prepare food. Compared with how things used to be, my son and I are now even more cheerful than I had thought possible".

This assumption was first written as, "Family attendees hope that they may serve as future models, and family facilitators become aware of their own recovery". However, a research participant suggested that it is not necessary to distinguish between attendees and facilitators, because they all learn from each other. All research participants agreed with this suggestion, leading us to change this assumption to its final form.

\subsection{Group Work Focusing on Families' Strengths and the Acceptance of Emotional Disclosure Is Linked to Reduced Self-Stigma}

Families of persons with mental illness suffer from public stigma, prejudice, and 
discrimination. Self-stigma occurs when people internalize these negative public attitudes and suffer adverse consequences as a result [20] [21].

The group work skills focused on families' strengths are used in this program. Family facilitators are trained in the skills with the metaphor of the boiled egg [22] [23]: Families must cope with the yolk of worries and difficulties, but the white of coping surrounds the yolk; this arrangement maintains the structure of the egg. Group work focusing on strengths is intended to elucidate family members' intrinsic strengths and lead them to "focus consciously on what families can do (the white of the egg)". This is similar to the strengths-based approach, which focuses on things the families are doing right and envisions life after they have overcome the problem [24].

This strengths-based work is supported by the reduction of self-stigma that results from the empowerment of families to share difficult stories and allow themselves to be accepted by their peers [20]. This approach also has elements of catharsis, one of Yalom's therapeutic factors. Discharging suppressed emotions that "could not be told because of shame" is therapeutic only in the context of genuine attempts to understand oneself or others [11]. A family attendee and research participants said the following in a newsletter, an article, and an interview:

"The family facilitators listened to us carefully and never contradicted us; they found things to praise and treated us warmly. It was very comforting to me".

"Family attendees who discharge their suppressed, painful experiences are then accepted by peer families. Through this process, they reaffirm their intrinsic power which they intent to accept objective realities, though they have ever considered reality negatively".

"A family attendee had hidden his son's illness to his relatives. However, during this program, he changed his attitude and decided to disclose the mental illness. I felt that he had relieved some of his self-stigma and taken a load off his mind".

\subsection{Group Facilitation with Omotenashi and Teamwork Skills in Family Facilitators Accelerate Positive Group Dynamic and Interaction among Group Members}

Family facilitators learn and practice basic group facilitation skills with the mind of omotenashi. In this program, a Japanese word omotenashi means "thoughtfulness towards family attendees, so that they feel a satisfaction in coming; offering a courteous welcome to other family attendees with hurt feelings and appreciating their painful experiences". Such a skill is necessary for successful group facilitation that leads to positive group dynamic. Japanese culture has long implemented omotenashi into its customer service philosophy in order to meet guest expectations [25].

The equal teamwork among family facilitators practice working together as equals while they prepare for and run the program. Good teamwork also accelerates positive group dynamics, which in turn are developed through between- 
member interaction; as would be expected, teams with higher levels of cohesion due to active member interaction are expected to have better performance [26], which is supported by theories on teamwork. As one research participant wrote in a journal:

"The family facilitators meet many times during group preparation to discuss how to make family attendees feel satisfied with their participation. The process produces effective teamwork and egalitarian relationships in which the facilitators appreciate each other. As a whole, good teamwork leads to positive group atmosphere".

\section{Discussion}

This study describes the seven assumptions underlying the program that families recognize.

\subsection{Program Components}

As shown in Table 1, we identified three types of program components: program form, learning style, facilitation skills. Assumption 1 includes program components regarding program form: family-led peer group, closed-membership, 5 times per course, and small group. Ninomiya [8] showed that higher fidelity on program form leads to decrease isolation of family facilitators. In this study, research participants recognize that such a form relates to program process including universality, high cohesion, effective group dynamics rather than direct outcome.

The program components regarding learning style are also found: combination of textbook and experiential knowledge, family peer learning, and sharing experiences. The research participants considered that such components lead to program process including insight, self-awareness and hope, and that the family attendees and facilitators reached outcomes including embeddedness of knowledge through such program process.

The assumption 6 and 7 include program components regarding facilitation skills: group work focusing on families' strengths, the acceptance of emotional disclosure, omotenashi, and teamwork skills. The research participants considered that increased interaction promotes the discharging suppressed emotions leading to the reduction of self-stigma. These results give additional considerations to the previous study that facilitation skills and attitudes of family facilitators were related to increase self-efficacy of family attendees [8].

Based on positive group dynamics caused by program form (Assumption 1) and group facilitation (Assumption 7), knowledge-related experience sharing leads families to couch their knowledge in an intimate and relevant context, which allows them to gain insight and self-awareness (Assumption 2). This family-led peer-learning style produces a synergetic effect by combining knowledge embeddedness and acceptance of disability (Assumption 3). Through sharing their experiences, they also learn how to handle the related issues (Assumption 4) and many families find hope and become aware of the extent of their own re- 
covery (Assumption 5). Families recount their own experiences while simultaneously reading the textbook; by accepting themselves openly and being accepted by their peers, they reduce their self-stigma (Assumption 6). We discussed the relationships between seven assumptions and reached a conclusion that all program components are connected with sharing experiences. Therefore, the core component of this program might be sharing experience.

\subsection{Significance of Sharing Experiences}

When they share their experiences with each other, family members of persons with mental illness are allowed to tell their stories that were too difficult to tell previously. These not-yet-said stories can adversely impact one's identity, since the self is developed through telling one's own story [27]. Telling stories about themselves led families to organize their own stories and see themselves from an outside perspective; through this, they gained insight and self-awareness. People come to know who they are through sharing themselves with others [14]. People live and understand their lives through socially constructed narrative realities, which give meaning and organization to their experiences [13]. In the program, families share and understand their experiences by co-constructing narrative realities with others. As the families realized that "I felt the same as [the others]", their mutual acceptance and empathy was strengthened. This empathy tends to be especially deep and can be perceived as more meaningful than sympathy from those who have not experienced a mental illness in the family.

Self-help groups aim to provide a safe place for people to tell their stories [27]. In this program, no one advises anyone else; the families listen to each other with respect, knowing that all group members are equal, and they understand each other's pain. Through this program, family attendees tell their important not-yet-said stories, which are accepted by other members; in turn, this allows them to accept their own true selves. This is similar to the process undergone by clients and therapists in private therapy, in which not-yet-said stories are cocreated mutually [13]. The not-knowing actions and attitudes of therapists express a need to know more about what the client has said [13], similar to the attitudes of group members in this program. In this program, the telling of notyet-said stories leads to a change in the tone of the narrative from negative to positive. While this program differs from professionally facilitated therapy, it has many features in common with narrative therapy.

\subsection{Recommendations and Limitations}

This study identified program components that extracted from recognition of families who have developed and disseminated the program. We will revise the fidelity scale in response to the results for a more effective and efficient program. This study showed detailed descriptions of program components that could be useful for future family peer learning programs in other countries.

One of limitations might be discussion environment in the group setting. We asked research participants to discuss until agreement about tentative assump- 
tions. Its environment could have led to bias in favor of adopting any proposal mentioned. However, to address the limitation, we tried to encourage their opinions freely not to impose. Another limitation might be that the program components are perceived ones not objective ones. We need to verify their validations by quantitative studies in the future.

\section{Acknowledgements}

The Omotenashi-FELP was managed by a non-profit organization called COMHBO (Community Mental Health \& Welfare Bonding Organization). Financial support for the program was provided for non-commercial purpose by the Johnson \& Johnson Contribution Committee. All of the authors were volunteer project members of the program at the time of the study. Financial support for this study was provided by the Grant-in-Aid for Scientific Research (C), Japan (Grant number 23593453). The authors report no conflicts of interest.

\section{References}

[1] Chiba Prefecture Federation of Families of People with Mental Disorders (2009) Daily Life and Social Welfare Needs of People with Severe Mental Disorders and Their Families Living in the Community in Chiba Prefecture. Community Mental Health \& Welfare Bonding Organization, Ichikawa.

[2] Reay-Young, R. (2001) Support Groups for Relatives of People Living with a Serious Mental Illness: An Overview. International Journal of Psychosocial Rehabilitation, 5, 147-168.

[3] National Association of Mental Health and Welfare (2010) Report Regarding Effective Family Support and Others for Families to Live in Relief by Promoting Persons with Mental Disorders' Independent Living in Community. National Association of Mental Health and Welfare, Tokyo.

[4] Dixon, L.B., Lucksted, A., Medoff, D.R., Burland, J., Stewart, B., Lehman, A.F., Fang, L.J., Sturm, V., Brown, C. and Murray-Swank, A. (2011) Outcomes of a Randomized Study of a Peer-Taught Family-to-Family Education Program for Mental Illness. Psychiatric Services, 62, 591-597.

https://doi.org/10.1176/ps.62.6.pss6206_0591

[5] Pickett-Schenk, S.A., Cook, J.A. and Laris, A. (2000) Journey of Hope Program Outcomes. Community Mental Health Journal, 36, 413-424. https://doi.org/10.1023/A:1001913013197

[6] Chiu, M.Y.L., Wei, G.F.W., Lee, S., Choovanichvong, S. and Wong, F.H.T. (2011) Empowering Caregivers: Impact Analysis of FamilyLink Education Programme (FLEP) in Hong Kong, Taipei, and Bangkok. International Journal of Social Psychiatry, 59, 28-39.

[7] Solomon, P. (1996) Moving from Psychoeducation to Family Education for Families of Adults with Serious Mental Illness. Psychiatric Services, 47, 1364-1370. https://doi.org/10.1176/ps.47.12.1364

[8] Ninomiya, S. (2012) A Formative Evaluation of "Family-to-Family Evaluation" Program, a Peer Support Program for Families of Persons with Mental Illness. Graduate School of Japan College of Social Work.

[9] Weiss, C.H. and Connell, J.P. (1995) Nothing as Practical as Good Theory: Exploring Theory-Based Evaluation for Comprehensive Community Initiatives for Children and Families. In: New Approaches to Evaluating Community Initiatives. Con- 
cepts, Methods, and Contexts, The Aspen Institute, 65-92.

[10] Glaser, B. (1978) Theoretical Sensitivity: Advances in the Methodology of Grounded Theory. The Sociology Press, Mill Valley.

[11] Yalom, I. and Leszcz, M. (2005) The Theory and Practice of Group Psychotherapy. 5th Edition, Basic Books, Cambridge.

[12] Katz, A.H. (1970) Self-Help Organizations and Volunteer Participation in Social Welfare. Social Work, 15, 51-60.

[13] McNamee, S. and Gergen, K.J. (1992) Therapy as Social Construction. Vol. xi, Sage Publications, Inc., Thousand Oaks.

[14] Funatsu, M. (2002) Narrative Construction Theory of the Self. Journal of Faculty of Sociology, Toyo University, 40, 75-88.

[15] Gergen, K.J. and Gergen, M.M. (1983) Narratives of the Self. In: Studies in Social Identity, 255-273.

[16] Spaniol, L. (2010) The Pain and the Possibility: The Family Recovery Process. Community Mental Health Journal, 46, 482-485.

https://doi.org/10.1007/s10597-010-9315-3

[17] Lucksted, A., Stewart, B. and Forbes, C.B. (2008) Benefits and Changes for Family to Family Graduates. American Journal of Community Psychology, 42, 154-166. https://doi.org/10.1007/s10464-008-9195-7

[18] Borkman, T. (1976) Experiential Knowledge: A New Concept for the Analysis of Self-Help Groups. Social Service Review, 50, 445-456. https://doi.org/10.1086/643401

[19] Lazarus, R. and Folkman, S. (1984) Stress, Appraisal, and Coping. Springer Publishing Company, New York.

[20] Corrigan, P.W. and Rao, D. (2012) On the Self-Stigma of Mental Illness: Stages, Disclosure, and Strategies for Change. Canadian Journal of Psychiatry, 57, 464-469.

[21] Corrigan, P.W. and Watson, A.C. (2002) The Paradox of Self-Stigma and Mental Illness. Clinical Psychology: Science and Practice, 9, 35-53. https://doi.org/10.1093/clipsy.9.1.35

[22] Tsuchiya, T. (2006) Start-Up Reading Book for Family Education Program-Psychiatric Version. Psychiatric Mental Health Nursing Publishing, Inc., Tokyo.

[23] Mitsumoto, K. (1997) Self-Reflection Psychotherapy. Gokei Printing Co., Ltd., Tokyo.

[24] Anuradha, K. (2004) Empowering Families with Mentally Ill Members: A Strengths Perspective. International Journal for the Advancement of Counselling, 26, 383-391. https://doi.org/10.1007/s10447-004-0174-x

[25] Nakano, L. (2008) Hospitality-Omotenashi: Comparing Apples to Oranges. Japan Spotlight, 27, 32-35.

[26] Hackman, J.R. (1987) The Design of Work Teams. In: Handbook of Organizational Behavior, Prentice Hall, Upper Saddle River, 315-342.

[27] Asano, T. (2001) Narrative Approach to the Self: Family Therapy to Sociology. Keiso Shobo Publishing Co., Ltd., Tokyo. 
Submit or recommend next manuscript to SCIRP and we will provide best service for you:

Accepting pre-submission inquiries through Email, Facebook, LinkedIn, Twitter, etc. A wide selection of journals (inclusive of 9 subjects, more than 200 journals)

Providing 24-hour high-quality service

User-friendly online submission system

Fair and swift peer-review system

Efficient typesetting and proofreading procedure

Display of the result of downloads and visits, as well as the number of cited articles Maximum dissemination of your research work

Submit your manuscript at: http://papersubmission.scirp.org/

Or contact ojn@scirp.org 